\title{
ReCUERDOS DE UNA POSIBLE HISTORIA DEL PORVENIR DE CARLOS RINCÓN*
}

\author{
Karlheinz Barck ${ }^{1}$
}

\begin{abstract}
* Leído en el Instituto Latinoamericano de la Freie Universität de Berlín el 23 de enero de 2003 en el acto de Emeritierung, por el doctor Karlheinz “Carlo" Barck (1934-2012), destacado filólogo alemán, estudioso del modernismo hispanoamericano y francés, así como de las teorías e historias de la literatura. Investigador del Zentralinstitut für Literaturgeschichte der Akademie der Wissenschaften, y uno de los impulsores del Ästhetische Grundbegriffe, el notable Diccionario de nociones estéticas en siete volúmenes -en el cual participó Rincón con tres entradas: magia/mágico, exótico/ exotismo y primitivo/primitivismo-.
\end{abstract}

Cómo citar este artículo: Bark, K. (2021). Recuerdos de una posible historia del porvenir de Carlos Rincón. Estudios de Literatura Colombiana 48 pp. 129-132. DOI: https://doi.org/10.17533/udea.elc.n48a08

1 https://www.zfl-berlin.org/people-detail/ barck.html

Leibniz-Zentrum für Literatur- und Kulturforschung, Deutschland

Editores: Andrés Vergara Aguirre, Christian Benavides Martínez, Valentina Noreña Gómez

Recibido: 09.12 .2020

Aprobado: 09.12.2020

Publicado: 18.12 .2020

Copyright: @2021 Estudios de Literatura Colombiana. Este es un artículo de acceso abierto distribuido bajo los términos de la Licencia Creative Commons AtribuciónNo comercial - Compartir igual 4.0 Internacional

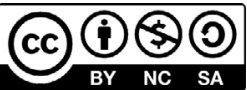

No se va a tratar de un discurso de profecía o de vaticinio, sino nada más que saludando a nuestro homenajeado recordando una encrucijada en su vida - y en la nuestras conjunta - que descifro como una constelación o como una coyuntura feliz por el hecho de contener momentos y figuras de una historia biográfica del porvenir de CR que celebramos hoy aquí en su presencia con nuestros votos para lo que él y en este caso yo como colega suyo podemos imaginar como otra etapa prolongada de estas figuras que quiero recordar.

Decía que las veo enredadas en una constelación feliz y esto es algo como una profession de foi de mi parte, porque he tenido la suerte de haber podido compartir y acompañar de cerca, durante algún tiempo y mediante un diálogo amistoso y comprometido, la generación (o la incubación) a través de altos y bajos de nuestro ambiente histórico, cultural y político, de signos y señas de la personalidad de $\mathrm{CR}$ originados o, mejor dicho, ocasionados por anhelos y encuentros de un joven peregrino entre ambos mundos, agent de liaison cultural podríamos llamarlo, que tenía en su constitución y formación intelectual algo que le servía de empuje hacia lo in- 
esperado, hacia lo maravilloso, lo desconocido y lo insólito - hacia lo utópico tal vez, que yo calificaría de duende ovidiano que, a veces, puede tomar la forma disfrazada de diábolo-.

Y efectivamente, es por tal duende ovidiano de metamorfosis que los pasos del peregrino CR le llevaron a principios de los años sesenta del ya pasado siglo desde su ciudad natal hacia la ciudad de Leipzig que en aquel entonces llevaba el apodo de Metropolis del Espiritu - Hauptstadt des Geistes (donde enseñaban filósofos tan importantes como Ernst Bloch y Hans Gadamer)—. Este trayecto fue más que un paso a través de territorios geográficos distintos desde un mundo a otro, uno en sentido cultural, científico y político a la vez. Teniendo en cuenta que las metamorfosis no son solamente algo como el campo preferido para la invención de lo maravilloso, sino que — como sabemos los reunidos aquí en su honor- constituyen además en su forma del mundo mágico de Macondo y de lo real maravilloso americano un área de las investigaciones (y de los sueños) de CR. Podríamos decir que la llegada del joven CR a Leipzig en aquel entonces, en plena guerra fría, tenía aspectos de un acto surreal -o surrealista-. Y fue exactamente como se lo imaginaba Werner Krauss, quien iba a ser el maestro - el Doktorvater - de CR en estos años sesenta, ¡que de una u otra forma han sido nuestros años decisivos! El gran romanista Werner Kraus, el Viejo, como solíamos llamarlo, anotaba bajo la fecha de febrero de 1964 esta observación:

„!. Ein junger Kolumbianer brachte mir ein Buch von Ramón Gómez de la Serna, La sagrada cripta del Pombo II (Madrid 1926), wo ich folgendermaßen erwähnt bin: Werner Krauss, ein deutscher Rebell, der uns erzählte, in Deutschland würde man den Kellner „Herr Ober“ nennen und den Überrock „Bratenrock“, und dass selbst die Feierlichkeiten nach einer Beerdigung mit einem Bankett enden."

CR asumía un papel muy especial en el debate sobre el arte y las literaturas modernas de vanguardia en medio del controvertido ambiente real-socialista de estos años, por haber contribuido de manera universalista inmediatamente después de la defensa de su tesis doctoral titulado El teatro de Federico García Lorca a una subversión del horizonte hermético y dogmático - lukácsiano, podríamos decir para ser rápidos- que reinaba y dominaba en la RDA de entonces. No es exagerado decir que $\mathrm{CR}$ ha sabido orientar y organizar durante su Residencia en tierra alemana algo como un fórum para las literaturas modernas española y latinoamericana. Fue suyo el papel de embajador de letras que pudo realizar incansablemente con el apoyo de amigos y colegas fuera 
y dentro de las instituciones como, en primer lugar, en las tres editoriales que han publicado sus ediciones cuidadosas de novelas y antologías de ensayos y de poesía: Reclam-Verlag de Leipzig y las editoriales Aufbau y Volk und Welt en Berlín. La lista respetuosa de estas ediciones suyas que en su mayoría daban acceso por primera vez en lengua alemana a escritores y poetas de España y de América Latina - también de Portugal y de Brasil - consta p. e. de Rafael Alberti, Pablo Neruda, Jorge Luis Borges, Luis Buñuel, Ernesto Cardenal, Rubén Darío, Carlos Fuentes, Federico García Lorca, Gabriel García Márquez, Diego de Landa (con su Relación de Yucatán), Carlos Monsiváis. Este eminente trabajo de transmisión y de recepción intelectual no hubiera sido posible sin la participación y ayuda de excelentes traductores que CR ha sabido asociar a sus proyectos. De este equipo quiero nombrar en primer lugar a su compañera Gerda Schattenberg, al inolvidable Erich Arendt, a quienes los alemanes deben sus traducciones de Neruda y Góngora, y a Fritz Rudolf Fries, fieles compagnons de route de CR en sus quehaceres de embajador intercultural.

Metamorfosis fue todo este trabajo en muchos sentidos. Así es que no por acaso CR presentaba la Antología de poesía española moderna que Reclam publicó en el año 1968 con un verso de Federico García Lorca titulado Metamorfosis del clavel.

Y el duende ovidiano seguía disturbando y perturbando los sueños de CR. Así que a finales de nuestros años sesenta publicó en Sinn und Form, revista de la Academia de Artes, un largo ensayo sobre su visión de la Cultura de la Contra-Conquista en América Latina bajo el título significativo Metamorfosis de un descubrimiento (!). Este ensayo con tintes de manifiesto fue en Alemania una de las primeras contribuciones de una deconstrucción del eurocentrismo cultural avant la lettre en este terreno, movido, diría yo, por este duende ovidiano que me complazco en identificar aquí en la persona y en la obra de CR. En este ensayo CR tomaba como punto de partida - como Fluchtpunkt - el famoso capítulo Des Coches que forma parte de los Essais de Montaigne. Y de ahí la vuelta durante los años setenta, mientras CR colaboraba en un proyecto que el maestro Werner Krauss dirigía en la Akademie der Wissenschaften en Berlín, vuelta entonces hacia la cultura de la época de la Ilustración para analizar en detalle (y a partir de documentos archivísticos descubiertos por él) los caminos intelectuales y culturales que seguía el espiritu de las luces entre Europa y América.

Si lo veo bien, es el gran ensayo que escribía CR sobre la Begriffsgeschichte de la noción Ilustración en el siglo XviıI español (¡es el primer trabajo sobre el tema!) que le 
ayudó para darle a su duende ovidiano ciertas alas metodológicas, en un sentido que en este momento se desarrollaba como una nueva teoría y metodología de la historiografía. A partir de estas experiencias en materia de historia semántica fue casi un compromiso natural que firmamos con un apretón de manos cuando CR aceptó con alegría escribir estos tres ensayos para el diccionario Ästhetische Grundbegriffe en siete tomos (Diccionario de nociones estéticas) en los cuales analiza los conceptos magia/mágico, exótico/ exotismo y primitivo/primitivismo. Todos han sido publicados en los tomos $3 \mathrm{y}$ 4 de este diccionario donde ustedes pueden seguir los pasos de nuestro peregrino, y comprobar si están a la altura de las andanzas

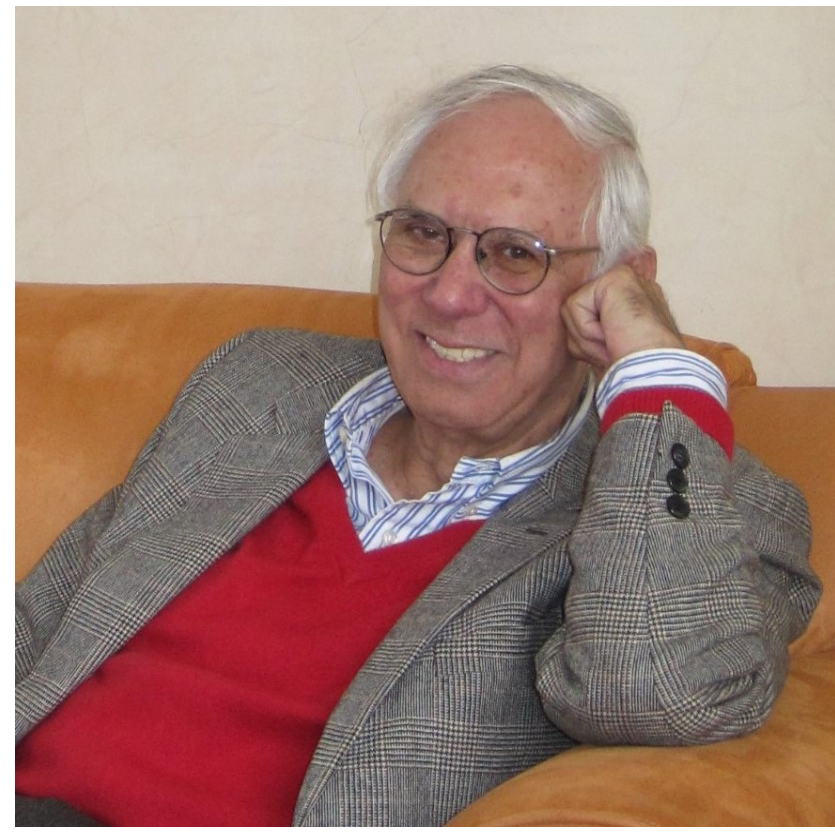

Carlos Rincón (Colombia,1937 - Alemania, 2018)

Fuente: Archivo personal de Gerda Schattenberg $\mathrm{y}$ aventuras de la scientific community.

A mí me queda agradecerte, amigo Carlos, y presentarte mis votos para que continúes echando puentes entre ambos mundos, configurando otra historia más del porvenir a cuya visión podamos tal vez añadir en esta ocasión de tu jubilación nuestro júbilo y regocijo, en vista de otras metamorfosis que espero van a surgir, imaginadas por el duende ovidiano de tu taller. 